\title{
Breve estudio y comentario sobre un Municipio inglés. The Royal Town of Sutton Coldfield
}

Uno de los antiguos concejales del Ayuntamiento de Guecho quefrecuentaba la población inglesa de Sutton Coldfield tuvo la oportunidad de ser invitado especialmente a una de sus sesiones, y con este motivo se cambiaron varias Memorias y folletos entre ambos Municipios, que dieron a conocer al nuestro detalles del funcionamiento del inglés y los distintos aspectos de su administración, que, por cierto, atiende a las más variadas funciones, como después se verá.

La circunstancia de tener ambos Ayuntamientos alguna analogía me ha movido a dar una sintesis de lo que abarca la administración del. Municipio de Sutton, por si pudiera servir de ejemplo entre nosotros.

Para hacer este estudio me sirvo de la Memoria lujosamente editadà y con ilustraciones, correspondiente'al año 1950, "Activities and Administration», que comienza con un cordial saiudo de su Alcalde.

Sutton Coldfield en aquella feaha era una antigua población de unos 50.000 habitantes, formada por varios Distritos, llamados Wylde Green-Maney + WalmleyłBoldmere West-Trinity-Hill y Boldmere East. Se halla, en el condado de Warwich, a 11 kilómetros al NE. de la populosa ciudad industrial de Birmingham, con la que está prácticamente unida, pues sọn varias las calles que están trazadas sin tener en cuenta el limite jurisdiacional, de modo que, de hecho, no hay separación entre ambas poblaciones, aunque conservan su administración independiente.

Posee Sutton Coldfield un hermoso parque de 2.400 acres ó $\mathbf{9 7 0}$ hectáreas aproximadamente, y. su situación es muy grata, por cuya: 
razón han estabiecido en ella su residencia los ricos negociantes fe Birmingham.

El crecimiento de su población ha sido como sigue:

En el año 1902 tenía 15.635 habitantes y 3.250 edificios.

En el año 1920 tenía 21.684 habitantes y $\mathbf{5 . 3 0 0}$ edificios.

En el año 1940 tenía $\mathbf{4 0 . 6 3 0}$ habitantes y $\mathbf{1 2 . 6 0 0}$ edificios.

En el año 1949 tenía 47.440 habitantes y 13.767 edificios.

El área de la jurisdicción es de $\mathbf{1 3 . 9 7 8}$ acres, equivalente a $\mathbf{5 . 6 5 5}$ hectáreas.

Se ve, pues, la gran analogía del Municipio inglés con el de Guecho en cuanto a la bella situación geográfica de éste, a su cercania a Bilbao y a que su zona sea residencial. El aumento de la pobla ción se ha desarrollado, a saber:
En el año 1857 contaba 2.079 habitantes.
En el año 1900 contaba 5.445 habitantes.
En el año 1920 contaba 11.399 habitantes.
En el año 1940 contaba $\mathbf{1 7 . 7 9 5}$ habitantes.
En el año 1948 contaba 20.093 habitantes.

Después de estos datos estadísticos voy a dar un ligero resumen de las modalidades administrativas del Ayuntamiento de Sutton, presidido por el Honorable Alcalde-His Worship Mayor.

E1 Concejo se compone de 28 miembros: siete Tenientes de Alcalde (Aldermen), uno para cada Distrito, y 21 Consejeros (Councillors).

El Ayuntamiento está dividido en siete Comisiones, de tres Concejales cada una.

Los Concejales se relevan cada tres años, y la duración del cargo es de seis.

El Concejo debe reunirse, según la ley, cada cuatrimestre; pero celebra sesión todos los meses, excepto agosto.

Se elige Alcalde cada tres años, en la reunión de mayo.

Los Concejales usan en las sesiones toga escarlata, y azul los Tenientes de Alcalde. El Alcalde, además de la gran toga, lleva doble collar, del que pende el escudo de la ciudad, y asa birrete.

Las sesiones son públicas, y detrás del Ailcalde se hallan los maceros, con lujosas vestiduras.

El Ayuntamiento tiene en su plantilla los siguientes cargos: Clé- 
Iigo y Abogado, Tesorero, Médico, Ingeniero y Sobrestante y Bibliotecario.

La Deuda municipal aparece cifrada en 1.280.908 libras y el Pre-

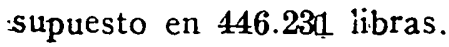

Tiene Sutton seis parques muy extensos y cuidados; uno de ellos, el Sutton Park, ya citado, fué propiedad de Enrique VIII y continuó como propiedad de la Corona hasta 1886 , en que fué cedido a la Municipalidad. La entrada al parque es de pago, tanto para las personas como para los coches, y produce una gran recaudación. Tiene en su interior grandes espacios dedicados a lagos y piscinas, en los que se bañan los vecinos y se practica el deporte de pesca y vela. También hay' pistas ide patinaje, golf y equitación. Las principales especies arbóreas son roble, abedul y acebo. En las lagunas y cursos de agua se dam el sauce y el a 4 isio, que se renuevan en gran escala. Los árboles proporcionan un buen ingreso al Ayuntamiento. En el parque se crian zorros, conejos, ardillas y otras especies. Sobre los lagos se ven patos y cisnes. La pesca y la caza son muy codiciadas. y las regula el Ayuntamiento. Parques de menor importancia son el Rectory, el Ley Hill, el Playeng Fields y otros. Buen número de deportes y atracciones tienen iugar en estos parques.

Basta lo extractado para darse alguna. idea de lo que son estos parques municipales de Sutton, y fuera de desear que tuvieran aquí ejemplo, porque cada día es más importante la función social de parques y jardines.

Las atenciones de tipo municipal que destaca la Memoria que comento son múltiples. Omito detallar las más elementales y las que, por otro lado, tienen semejanza con las de los Municipios españoles.

Para el objeto de este artículo voy a fijarme en aquellas funciones que difieren de las nuestras. Por cierto que vemos algunas que en España se llevan por los Juzgados. Sostiene Sutton una Biblioteca pública con más de $\mathbf{7 0 . 0 0 0}$ vo'úmenes.

En el orden de la enseñanza atiende a la primera y segunda, contando también con Escuelas de Artes y Oficios. Tiene un servicia para prevención de accidentes en la carretera y otorga las licencias de conducir. Pero las funciones de más interés que abarca el Municipio de Sutton son las que se agrupan en la Memoria bajo el epígrafe "Programa de actividades», cuyo número alcanza a 56. Entre ellas vemos las más variadas atenciones.

Unas veces es el propio Ayuntamiento el que las lleva a cabo, y en otras actúa en colaboración con diversos grupos de vecinos. Sobre 
todo, son de notar los muchos deportes que sostiene el Municipio. inglés. Se ve, pues, mayor engranaje que en nuestros Municipios en: el inglés y sus entidades artisticas y deportivas.

Según los datos que vamos examinando, en Sutton hay dos Asociaciones que cultivan el arte dramático, una Compañia artística del Teatro municipal, una sala de concientos, de la cual es Vicepresidente un Concejal. La sala de la Música de la Opera la preside el Alcalde. Funcionan varias masas corales, una Asociación fotográfica, una de cine y una de la Cruz Roja.

Entre las Asociaciones doportivas vemos que en la primera de estas Sociedades de la Villa ocupa la Vicepresidencia el Alcalde. E1 Club de Criket lo preside un Concejal. Funcionan clubs de rugby, hockey y dos de golf, uno de los cuales lo preside el Alcalde. Existen también una Sociedad de pescadores de caña y una de ajedrez.

También funcionan Sociedades de Ingenieros y de extensión universitaria.

De la de Horticultura es Vicepresidente el Alcalde. Son curiosas las Sociedades de mejora de jardineros, de aves de corral y una Asociación canina y el Club de señoras amantes de jardines. La Sociedad del servicio voluntario de señoras la preside la Alcaldesa, así como el. Gremio de señoras y la Asociación eléctrica de mujeres. Más curiosa aún es la Asociación de mujeres para enseñar a manejar a sus asociadas los aparatos caseros modernos.

En el orden administrativo, las funciones del Ayuntamiento de Sutton tienen bastante analogía con las nuestras.

Para las sesiones del Pleno se reparte a todos los Concejales un folleto impreso, en el cual se insenta el orden del día y las resoluciones a cada una de las minutas tratadas por los Comités, los cuales equivalen a nuestras Comisiones.

Entre los datos recibidos del citado Municipio inglés se halla el orden del día para una de sus sesiones. Se trataron en ella 245 asuntos, que van también numerados, cifra importante, como puede verse.

Los Comités son los siguientes: Grandes Vías de Comunicación, Parques y Edificios, Sanidad, Bibliotecas y Artes, Urbanismo, Vivienda, Hacienda y Asuntos Generales. 'Como se ve, no difieren mucho de las Comisiones informativas de nuestros Ayuntamientos.

Expuestas ya las modalidades por que se rige el Municipio inglés de Sutton, es de interés establecer un parangón con los nuestros, $\mathbf{y}$ con el de Guecho en particular, para sacar las consecuencias que pue- 
den servir de nuevas orientaciones y que en su día puedan recogerse en nuestra legisłación local.

Se ve, ante todo, que el Municipio de Sutton, con 50.000 habitantes aproximadamente, tenía en 1950 un Presupuesto de $\mathbf{4 4 6 . 2 3 1}$ libras, que podemos estimar en $\mathbf{4 4 . 6 0 0 . 0 0 0}$ pesetas, cifra muy elevada si la comparamos con los Presupuestos españoles. Así acurre con el de Guecho, que con una población de $\mathbf{1 9 . 0 0 0}$ thabitantes tenía en ese fecha un Presupuesto de 5.300 .000 pesetas. $Y$ debe tenerse en cuenta que este Ayuntamiento es uno de los que tienen mayor Presupuesto, comparado con poblaciones españolas del mismo número de habitantes.

La menor disponibilidad de numerario de nuestros Municipios puede ser una de las causas por las que no puedan atender a muchisimas actividades.

No debe olvidarse que los ingleses llevan algunos servicios que en Ispaña los atiende el Estado por med: -út sus organismos, tales como la ICruz Roja, la expedición de licencia de conducir, la prevención de accidentes en las carreteras.

Otras atenciones que cuida el Municipio de Sutton, en España se explotan por medio de empresas privadas, que tienen salas de música para ópera, Sociedades corales, cines y otros espectáculos.

$\mathbf{Y}$ como las Haciendas de los Municipios españoles no pueden llevar adelante una serie de atenciones por los fuertes desembolsos que exigen, como ocurre con las urbanizaciones y otras de primer establecimiento, tienen que acudir a Presupuestos extraordinarios, cuya formalización y dotación es complicada y la tramitación demasiado lenta. Así se da el caso que los Presupuestos extraordinarios de algunas obras con proyecto aprobado se hacen inactuales, sobre todo en los tiempos que corremos, por tener que someterse a la lentitud de la tramitación aludida.

Esta escasez presupuestaria es el motivo por el cual el Ayuntamiento de Guecho, acuciado por otras atenciones urgentes, no haya podido hasta el día llevar adelante sus planes de urbanización, muy neceśarios, ni haya completado el arreglo de calles, ni tenga las playas con todos los servicios, ni su parque de Fadura, de unas 35 hectáreas, debidamente instalado, aparte un buen campo para concursos hípicos y otro de polo, por cierto muy elogiados; pero el resto del parque necesita otras mejoras, cuya demora redunda en perjuicio de 
su vecindario y del de Bilbao y su zona, que podrian encontrar en sus alamedas un lugar de gran atracción y descanso, como hemos visto ocurre en los grandes parques del Ayuntamiento de Sutton.

En el momento actual y en el futuro deben nuestros Municipios tener presente la conveniencia de dedicar a los deportes todos los esfuerzos posibles, concediéndoles mayor atención a fin de que en su organización esté presente el Municipio, y en ello hemos visto buen ejemplo en el de Sutton.

A este efecto debe comenzarse por cuidar que en los planes de urbanización de los pueblos y ciudades se dejen los espacios precisos para campos de toda clase de deportes, para juego de niños dentro y fuera de las manzanas de casas, y para que sirva de aliciente no debe olvidarse la gran variedad de juegos a los que atiende y colabora el Municipio de Sutton, muchos de los cuales son ya habituales entre nosotros.

Debe atenderse también por nuestros Municipios a la organización de los depontes que no estén atendidos por los particulares, o a colaborar en aquellos que tengan vida lánguida, a fin de conseguir la necesaria eficacia.

Otro aspecto que sugiere el estudio que comentamos es la gran variedad de actividades del Municipio inglés, y ello puede atribuirse a que estas Corporaciones inglesas gozan de cierta descentralización para desenvolverse, sin la cual no podría el de Sutton abarcar las variadas atenciones que hemos visto, las cuales comento con elogio. Acaso se deba este aspecto al carácter de los habitantes de la Gran Bretaña, tan diverso del nuestro.

No debe olvidarse que los inconvenientes aludidos que se presentan en nuestras Corporaciones para llevar adelante planes de primer establecimiento pueden acometerse solicitando el régimen especial de Carta, que se articula en la Ley de Régimen local vigente. Ahora bien, en los Municipios de mayor concentración urbana, pero con distinta fisonomía, no puede uno de ellos acogerse a ese régimen de Carta, porque, además de hacer impopular a la Corporación que la implantase, nacería esa reforma con pocas probabilidades de arraigo.

Merece la pena destacar como final de este artículo la dignidad que en Inglaterra se rodea a todos los cargos públicos, entre los cuales no podían faltar las preeminencias que alli tienen el Alcalde y los Concejales.

Ya en nuestra reciente Ley de Régimen local se ha tenịo en 
cuenta algo en este sentido al acordar el tratamiento que deben tener los Alcaldes y sus gastos de representación. Pero tos futuros legisladores deberian tener presente que todas las investiduras que se concedan a quienes regentan los cargos de la Administración local redundarán en beneficio de la propia función.

$$
\begin{gathered}
\text { José J. BaUtista Mérino URrutia } \\
\text { Alcalde de Guecho }
\end{gathered}
$$

